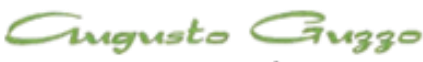

REVISTA ACADEMICA

\title{
O princípio do controle emocional na construção de uma liderança eficaz
}

\author{
Márcia Cristina Gomes Molina' \\ Recebido em: 05/09/2013. Aprovado em: 04/12/2013. Disponibilizado em: 20/12/2013
}

1. Mestranda em Ciências Humanas e Sociais pela Universidade Federal do ABC - UFABC e Professora universitária na Faculdade Anchieta - Unidade Faculdade Anhanguera de São Bernardo do Campo e nas Faculdades Metropolitanas Unidas - FMU.

\section{Resumo}

Com uma nova visão da área de Recursos Humanos, as empresas têm alavancado de forma surpreendente seus resultados, superando antigos paradigmas e desenvolvendo novas técnicas para otimizar as habilidades e competências de seus colaboradores.

Atualmente a área de Gestão de Pessoas desponta com novos propósitos e, está voltada à gestão estratégica, ressaltando a importância das pessoas na organização. Mediante essa transformação, a liderança torna-se um dos principais pilares que sustentam essa nova performance. Os líderes destacam-se como um dos pontos chaves neste novo cenário, demonstrando estar cada vez mais preparados e equilibrados emocionalmente para lidar com as diversas situações que ocorrem no dia-a-dia.

Esta pesquisa baseia-se em fontes bibliográficas, que classificam o equilíbrio das emoções como uma das competências fundamentais para o desenvolvimento de líderes eficazes e altamente capacitados, responsáveis por despertar o que há de melhor em seus colaboradores.

Palavras-chave: Liderança; Recursos Humanos; Emoção; Equilíbrio.

\begin{abstract}
With a new vision of Human Resources, companies have leveraged so surprising results, surpassing old paradigms and developing new techniques to optimize the skills and competencies of its employees.

Currently the area of people management is emerging with new purposes, and is focused on strategic management, highlighting the importance of people in the organization. Through this transformation, leadership becomes one of the main pillars that support this new performance. Leaders stand out as one of the key points in this new scenario, demonstrating increasingly be prepared and balanced emotionally to deal with the various situations that occur in day-to-day.
\end{abstract}

This research is based on bibliographic sources, which classify the balance of emotions as one of the core competencies for developing effective leaders and highly capable, responsible for awakening what is best in their employees.

Keywords: Leardership; Human Resources; Emotion; Balance. 


\section{Introdução}

Esta pesquisa foi elaborada com base em pesquisas bibliográficas sobre liderança e inteligência emocional. Despertava-me a curiosidade em estudar e compreender de forma clara e concisa, como os líderes de sucesso atualmente estão utilizando a inteligência emocional com eficácia, contagiando suas equipes e alavancando resultados surpreendentes.

Dentre tantas ferramentas, há um papel de destaque para a inteligência emocional, partindo do princípio que em um mundo mutante como estamos vivenciando hoje, cada vez mais fica em evidência o papel das pessoas nas organizações, afinal são as pessoas que conduzem os processos e implementam melhorias e soluções em busca de resultados positivos.

As pessoas estão mais informadas, e por isso, procuram em seu trabalho não só sua subsistência, mas principalmente reconhecimento. Toda pessoa tem a necessidade de se sentir útil, valorizada pelo que faz. Com base nessas informações e nesse novo padrão de colaborador, constatou-se que os grandes líderes estão utilizando a inteligência emocional com bastante êxito, para construírem equipes de alto desempenho e com grande fonte de energia positiva.

As características desse líder emocionalmente equilibrado são comuns a muitos de nós, é dotado de sensibilidade, alto poder de argüição, comprometimento com a equipe, demonstrado através de pequenos atos como: saber ouvir, aceitar opiniões, instigar a participação de todos e desenvolvendo competências emocionais suficientes para manter o equilíbrio da equipe.

Esta pesquisa não tem o intuito de trazer respostas para questionamentos tão complexos, porém somar opiniões, históricos e diversos pontos de vistas, de como o controle emocional de um líder pode propagar respeito, comprometimento, admiração e resultados para a organização.

\section{As diversas faces da liderança}

Desde os primórdios da humanidade as pessoas buscam respostas para a origem da liderança. Muitos estudos foram realizados através de análises de personalidade, inteligência, impulsividade, dentre outros, com a finalidade de identificar as principais características de um líder de sucesso. De uma forma geral, estas pesquisas têm o intuito de descrever a liderança, entender os diversos fatores que fazem com que ela seja eficaz ou nociva à organização e minimizar possíveis falhas no decorrer deste processo. Partindo, deste princípio, inúmeras definições sobre liderança surgem a cada dia, com o propósito de encontrar uma conceituação mais adequada para se entender profundamente seu significado, a fim de aplicá-la com maior eficácia, alcançando melhores resultados.

Limongi-França in Fleury (2002:259), diz que a "liderança é um processo social no qual se estabelecem relações de influência entre pessoas" e complementa "o núcleo desse processo de interação humana é composto de líder ou líderes, seus liderados, um fato e um momento social".

Para Davis (2002:150), “a liderança é o processo de encorajar os outros a trabalharem entusiasticamente na direção dos objetivos", e afirma que "sem liderança, uma organização seria somente uma confusão de pessoas e máquinas, do mesmo modo que uma orquestra sem maestro, seria somente músicos e instrumentos".

Segundo Willingham (2001:7), “as pessoas possuem uma necessidade inata de serem valorizadas. Necessitam que seu 
trabalho seja reconhecido" e ressalta que os grandes líderes destacam-se por encontrar em seus liderados "algo mais", que nem ao menos eles próprios conseguem ver, assim, conseguindo desenvolver este potencial até então, desconhecidos por si mesmos.

Willingham (2001:8) afirma que esse "algo mais" é o componente químico que une aptidões e habilidades específicas, atitudes e formas de pensamento e que o desempenho profissional das pessoas é influenciado pelas crenças dos líderes.

Em paráfrise, Goleman (2002:11) coloca que a "função básica dos líderes, consiste em imprimir em seus liderados um sentimento positivo. Isso acontece quando o líder cria ressonância - um reservatório de positividade que liberta o melhor que há em cada um. Em sua essência, pois, a missão básica da liderança é de cunho emocional”.

Hunter (2004) contextualiza que a importância da liderança nas organizações se torna muito clara, visto que no livro o autor enfatiza que o verdadeiro líder é aquele que sabe servir sua equipe, que está disposto a se desnudar de toda sua autoridade para ouvir o que sua equipe tem para agregar de valor as suas ações e o quão é essencial interagir e agir coletivamente.

Covey (2005: 409) afirma que "a liderança é uma escolha, construída de dentro para fora tendo como base o caráter. Grandes líderes libertam o talento coletivo e a paixão das pessoas, rumo à meta certa”.

Hunter (2004:25) descreve a liderança como "a habilidade de influenciar pessoas para trabalharem entusiasticamente visando atingir aos objetivos identificados como sendo para o bem comum".

No dicionário Aurélio, liderar significa "dirigir na condição de líder. Liderança". Quão simples esta conceituação, no entanto, o que vemos na vida real é um processo bem mais complexo, que envolve muito mais sentimento, engajamento, comprometimento e por que não dizer espiritualidade que nossa vã filosofia possa explicar.

\section{A trajetória das pesquisas sobre}

\section{liderança}

Muitos cientistas estão estudando de forma sistematizada e cientifica o processo de liderança, alguns afirmam que os primeiros estudos sobre liderança ocorreram na criação da pirâmide das necessidades de Maslow, em 1950, outros pesquisadores, asseguram que a liderança adquiriu aspectos comportamentais a partir da Administração Científica de Taylor. Fazem-se citações a McGregor como um dos percussores da importância da liderança com a criação da teoria X e Y. Embora haja cientistas, que destacam como pioneiro no pensamento sobre liderança, Maquiavel, 1913 - em O Príncipe (FRANÇA, 2002).

Segundo Goleman (1999), o mercado de trabalho está mudando, sendo que antigos parâmetros estão sendo reavaliados e estão cedendo lugar a novas formas de avaliações. O que percebemos atualmente, que somente o raciocínio lógico, nem tampouco, possuir habilidades matemáticas, são suficiente para se obter sucesso, mas principalmente desenvolver uma habilidade peculiar encontrada nas pessoas bem sucedidas: saber lidar com as suas próprias emoções.

Limongi-França in Fleury (2002:260), afirma que "na liderança atual observa-se uma grande preocupação acentuada com a formação de equipes e grupos de trabalho no processo de liderança, explicitada no conceito de liderança de alta performance, no qual o líder, é antes de tudo, um catalisador de talentos na formação de novas competências e garantia de resultados".

Para Hunter (2004:24), "sempre que duas ou mais pessoas se reúnem com um 
propósito, há uma oportunidade de exercer a liderança" e complementa que " a liderança se reduz a uma definição de quatro palavras : identificar e satisfazer necessidades".

Estudos realizados por Goleman (1999:15), constataram que o uso da inteligência emocional é base de grandes líderes, tendo em vista que a liderança e o trabalho estabelecem um elo voltado ao relacionamento entre pessoas.

\section{Grandes Líderes da História}

Ao pesquisarmos sobre liderança, é quase impossível não relembrarmos de pessoas que deixaram sua marca na história da humanidade. Existem muitos líderes que merecem ser lembrados, porém irei me ater a alguns nomes que são referência de modelos a serem seguidos por todos nós.

Um desses homens, que permanece vivo em nossa lembrança é Gandhi. Gandhi foi um exemplo de determinação e de liderança que permanece como mártir de solidariedade, de humanismo e servidão.

Hunter( 2004:64) afirma que "Gandhi era um homem que tinha menos de $1,60 \mathrm{~m}$ de altura e pesava cerca de cinqüenta quilos! Gandhi viveu em um país oprimido, com cerca de um terço de bilhão de pessoas, uma nação escrava do Império Britânico. Gandhi declarou que obteria a independência da Inglaterra sem recorrer à violência”.

E o final desta história, o mundo conhece, em 1947, não apenas o império Britânico deu a independência à Índia como recebeu Gandhi de braços abertos em Londres, como um herói.

Jesus Cristo, também em diversos artigos sobre liderança, foi lembrado como o maior líder que já existiu. Embora esta afirmação não tenha nenhum cunho espiritual, independente da religião de cada pessoa, é fundamental relembrar que Jesus Cristo, formou uma equipe, a qual chamava de discípulos e através dessa equipe revolucionou o mundo.

Souza (2007:124), relembra a trajetória de Nelson Mandela por um ideal o fim do apartheid - uma política de segregação racial que proibia o acesso dos negros à propriedade da terra e a participação política, obrigava-os a viver em zonas residências demarcadas e proibia o casamento de negros com brancos.

Em paráfrise, Souza afirma que Mandela é um grande exemplo de liderança, lutou por uma causa que se transformou em coletiva, em virtude de ter liderado não só o seu grupo em seu país, mas no mundo todo mesmo estando preso, com isso conseguiu alcançar seu objetivo maior: o fim da apartheid e eleições democráticas.

Um grande líder brasileiro É Jorge Gerdau, conforme comentários de Souza (2007:37), Jorge Gerdau começou a trabalhar aos 14 anos de idade, na fábrica do pai, em suas férias escolares, operando máquinas, convivendo com os operários, o que o auxiliou a ter uma visão realista da vida empresarial. Formou-se em Direito, e assumiu a presidência da siderúrgica Gerdau em 1983.

Atualmente, o Grupo Gerdau é composto por duas dezenas de empresas de metalurgia e siderurgia que produzem milhões de toneladas de aço por ano e empregam milhares de pessoas no Brasil, Uruguai, Argentina, Chile, Estados Unidos e Canadá.

Jack Welch é um dos líderes mais conhecidos no mundo todo. Sua trajetória de sucesso teve início na General Electric Company em 1960, mais conhecida como G.E.

Em 1981 tornou-se C.E.O da empresa. Durante os 20 anos que esteve à frente da 
companhia eliminou toda burocracia que a prejudicava, transformando-a em uma central elétrica dinâmica e respeitada, em virtude destas mudanças e do sucesso alcançado em suas ações na época lhe conferiram a posição de C.E.O. mais influente dos últimos tempos. Muitos executivos o consideram como um verdadeiro guru do mundo corporativo.

Ao se aposentar em 2001, Jack Welch escreveu sua autobiografia, onde relata fatos e descreve passagens interessantes sobre como ser um líder de sucesso, e também como não poderia deixar de ser, ele também passa grande parte do tempo viajando pelo mundo, falando com pessoas de todos os níveis hierárquicos da empresa e respondendo uma série de questionamentos e indagações sobre como liderar de forma eficaz.

Souza (2007:47) comenta sobre um grande líder "Dalai-Lama, é um dos mais fascinantes líderes mundiais. Nasceu em uma família de agricultores na aldeia de Takster, no leste do Tibet e aos dois anos de idade foi reconhecido por monges como a reencarnação da autoridade máxima do budismo tibetano".

Dalai-Lama luta até hoje de forma pacífica pela emancipação de seu país Tibet e peregrina pelo mundo pregando o amor, a dignidade e a humildade em seus discursos, não se deixando abater pelas adversidades da vida e com a certeza de que está deixando um grande legado à humanidade.

Como estamos falando de grandes líderes, não podemos deixar de falar sobre Madre Teresa de Calcutá, uma missionária que tinha o projeto de proteger, apoiar e recuperar os desprotegidos da Índia, que mobilizou o mundo com sua causa tão digna e tão solidária.

Se pararmos para pesquisar sobre os grandes líderes que marcaram época com seus idealismos, seus sonhos e seus propósitos cheios de vivacidade nos depararemos com muitas maneiras de liderança, entretanto, em todas elas, poderemos perceber que algo em comum que as une, o poder de perdão, o amor ao próximo e a capacidade infundada e quase que inexplicável de lidar com as emoções.

\section{A Inteligência Emocional}

Há muitas indagações acerca da importância da inteligência emocional e de como utiliza-la com eficácia no dia-a-dia, porém o que tem se percebido é uma avalanche de informações e treinamentos que vem transformando a vida nas organizações, mas que por diversas vezes não tem concretude para seus líderes e liderados.

É incontestável o quanto é primordial e imprescindível saber lidar com os nossos sentimentos para que possamos agregar mais valor a nossa empresa e consequentemente às pessoas que estão ao nosso redor, portanto, é fundamental a transparência ao tratarmos sobre inteligência emocional a fim de dar significado as nossas ações.

A inteligência emocional está relacionada a aptidão e a habilidade para automotivação, o autocontrole, a persistência, entre outras características essenciais ao alcance de objetivos de interesses comuns.

Goleman (1999:338) escreve que "a inteligência emocional é a capacidade de identificar nossos próprios sentimentos e os dos outros, de motivar a nós mesmos e de gerenciar bem as emoções dentro de nós, e em nossos relacionamentos".

Para Weisenger (1997:14), a "inteligência emocional é simplesmente o uso inteligente das emoções, isto é, fazer intencionalmente com que suas emoções trabalhem a seu favor, usando-as como uma ajuda para ditar seu 
comportamento e seu raciocínio de maneira a aperfeiçoar seus resultados".

Como podemos constatar na conceituação de ambos os autores, a inteligência emocional está relacionada em como motivar a si mesmo e as outras pessoas; persistir mediante obstáculos, saber canalizar as emoções em prol de algo positivo e construtivo; ter controle sobre seus sentimentos, desta forma agregando colaboradores motivados e com grande potencial criativo e comprometidos com os seus objetivos pessoais e com os objetivos organizacionais.

\section{A transição do Q.I. para o Q.E.}

Os primeiros estudos constatam que os testes de Q.I. foram introduzidos a partir da Primeira Guerra Mundial nos E.U.A. Com o passar dos anos, os testes de Q.I., no qual se quantificava o raciocínio lógico, foram perdendo espaço para os testes de Q.E., pelo qual se quantifica o grau de equilíbrio das ações de uma pessoa, diante de diversas situações do cotidiano. (GOLEMAN,1999).

É sempre importante frisar que as empresas são formadas por pessoas que se relacionam e que possuem objetivos pessoais e individuais, que por muitas vezes podem vir a ser comuns, no entanto, é necessário conhecer-se em primeiro lugar para que possamos entender e compreender o outro.

Não basta apenas ser inteligente ou ter uma boa formação, é preciso saber lidar com as emoções, ter equilíbrio para que se possa chegar à excelência. $\mathrm{O}$ líder emocionalmente eficaz é capaz de entender e controlar seus sentimentos para conseguir uma equipe homogênea e comprometida (GOLEMAN,1999).

Apesar de parecer fácil, a aplicabilidade da inteligência emocional é muito mais complexa, visto que não está relacionada ao fato de ser simpático, mas, em saber expressar de forma clara e direta o que não está correto e apontar o que é preciso melhorar.

De acordo com Goleman, a inteligência emocional é desenvolvida ao longo dos anos, e à medida que chegamos a maturidade, ela mostra-se mais evidente, devido as nossas experiências de vida que se acumulam e nos proporcionam maior habilidade em lidar com os nossos sentimentos.

\section{O papel das emoções em nossas atitudes}

Há indícios de diversos estudos sobre o verdadeiro significado da palavra "emoções". Mas o que na verdade esta pequena palavra pode fazer em nossa vida como seres humanos e profissionais? Como já foi citado anteriormente, com o surgimento da inteligência emocional, podemos concluir que é cada vez mais aparente o interesse de pesquisadores e estudiosos em medir a importância e o verdadeiro sentido das emoções em nossas vidas e de como conseguirmos conduzi-las de forma positiva.

Goleman (2001:18) instiga-nos a pensar sobre a inteligência emocional através de um trecho de sua bibliografia onde ressalta que "cada tipo de emoção que vivenciamos nos predispõe para uma ação imediata”. Dentro deste contexto Goleman afirma que "a emoção refere a um sentimento e seus pensamentos distintos, estados psicológicos e biológicos, e a uma gama de combinações, variações, mutações e matrizes. $\mathrm{Na}$ verdade, existem mais sutilezas de emoções do que as palavras que temos para defini-las".

Em uma passagem Weisinger (1997:23), descreve as emoções como sendo importantes ferramentas para o nosso desempenho profissional e como se faz necessário compreender nossos sentimentos. 
Em paráfrise, Weisinger (1997:23), o truque é usar suas emoções, fazer intencionalmente com que suas emoções trabalhem em seu benefício, usando-as para ajudar direcionar seu comportamento e a obter resultados. De acordo com Weisinger, "a inteligência emocional pode ser nutrida, desenvolvida e ampliada - não se trata de uma característica impossível de adquirir. A maneira de expandir sua inteligência emocional é aprender e praticar as técnicas e aptidões que a compõem - entre elas, a autoconsciência, o controle emocional e a motivação".

Willigham (2002; 2), questiona a grande dificuldade das empresas em tratar seus colaboradores como gente, gente que realiza os processos e não gente como processos. Willigham faz uma analogia muito interessante ao referirem-se as pessoas como "Gente não é máquina e nem mesmo comporta-se de forma lógica na maior parte do tempo. Não produz simplesmente por assim ter sido comandada. Não. Gente é criatura 85\% emocional e 15\% lógica, destaca de maneira muito entusiástica o inigualável papel das emoções em nossas vidas.

O nosso grande desafio é saber como lidar com essas emoções, que na maioria das vezes, nos sobressaltam, sem que ao menos pudéssemos nos dar conta e de que forma controlar sentimentos tão vulneráveis e imprevisíveis, fazendo com que reajam a nosso favor. Essas e outras inúmeras perguntas nos solapam a alma à procura de respostas que muitas vezes, ainda perpetuam no silêncio do desconhecido.

\section{Como controlar as emoções}

Para que possamos controlar nossas emoções, segundo Weisinger (2001:46) é importante entendermos que "O nosso sistema emocional é feito de diferentes componentes que interagem e precisam trabalhar juntos com eficiência para otimizar seu desempenho. Se os componentes deixam de trabalhar como deviam o sistema pode cair".

Esses componentes aos quais Weisinger se refere são os nossos pensamentos ou avaliações cognitivas; as nossas alterações fisiológicas ou atos de excitação e nossas atitudes ou tendências de ação.

Em paráfrise Weisinger (2001:46) escreve que "algumas pessoas afirmam que os pensamentos precedem as alterações físicas, ao passo que outros são de opinião contrária - e um grupo numeroso acredita que o comportamento vem antes dos pensamentos ou das alterações fisiológicas". E finaliza dizendo que o mais importante é compreender que as emoções são produzidas por uma interação desses três elementos em reação a um acontecimento externo e que ao controlá-los seremos capazes de controlar eficazmente nossas emoções.

De acordo com Goleman (2001:97), classifica o fato de controlar suas emoções como autocontrole, que se resume em administrar com eficácia emoções e impulsos perturbadores.

Para Goleman as pessoas com essa competência sabem gerenciar bem seus sentimentos impulsivos e emoções aflitivas; manter-se compostas, positivas e impassíveis, mesmo em momentos difíceis e conseguem pensar com clareza e se manter concentradas mesmo sob pressão.

Pesquisas realizadas por Goleman ressaltam o controle das emoções como a capacidade do líder de manter um grupo trabalhando bem é por si só, um talento precioso. E quanto maior for à complexidade da tarefa, mais necessário tornam-se pessoas desse tipo, para se alcançar o êxito.

Weisinger (2001:47) ressalta que "compreender seu contexto emocional é uma ótima coisa, mas a solução nesse caso é 
colocar em ação, com força total, seus instrumentos de controle das emoções".

Enfim, o que podemos apurar sobre a importância do controle da emoção em nosso dia-a-dia é primordial para que saibamos contornar os sobressaltos que ocorrem em nossa rotina de trabalho, assim como utilizálas para criar, inovar e desenvolver novos projetos, quebrar antigos paradigmas e crescer profissionalmente.

\section{A inteligência emocional como vantagem competitiva}

Atualmente, muito tem se ouvido ou lido a respeito da inteligência emocional e como as organizações de sucesso estão preocupadas em alcançar a excelência em seus produtos e serviços, toda essa busca insaciável por informações, treinamentos, têm transformado a vida nas empresas e principalmente das pessoas que nela estão inseridas.

Apesar de ser considerado como algo novo, talvez a liderança emocional já venha sendo colocada em prática há muitos anos. Goleman (2002:5) afirma que "a tarefa emocional do líder é primal - ou seja, a primeira - em dois sentidos: é tanto o mais original como o mais importante ato de liderança e destaca como sendo os primeiros líderes da humanidade chefes tribais ou xamãs - que conquistaram seus postos em virtude de sua liderança emocionalmente vibrante".

Partindo deste princípio Goleman (2002:5) nos faz refletir com a seguinte frase "Ao longo da história e em culturas de todo o mundo, o líder de qualquer agrupamento humano sempre foi aquele a quem os demais recorrem em busca de conforto e clareza diante de determinada incerteza ou perigo, ou quando há algum trabalho a fazer. É quem funciona como líder emocional do grupo".
E o que podemos observar hoje em dia que nas corporações modernas, essa tarefa emocional continua desempenhando seu principal papel na assertividade da liderança: canalizando as emoções coletivas em uma direção positiva, com a finalidade de eliminar barreiras que possam prejudicar o propósito da empresa e das pessoas que nela estão inseridas.

Goleman classifica essa capacidade de canalizar as emoções de duas formas: liderança ressonante e liderança dissonante.

A liderança ressonante está relacionada à capacidade do líder de estimular as emoções de forma positiva, construindo um elo emocional com a equipe, enquanto a liderança dissonante vai de encontro a este propósito, ou seja, a liderança dissonante está relacionada com a falta de harmonia. A liderança dissonante transforma equipes em membros que têm a sensação de estar o tempo todo fora de tom, do compasso das coisas.

Segundo Goleman (2002:22), “a dissonância desencoraja as pessoas, desanima-as, ou as afugenta".

De posse dessas informações e retornando a história do homem, veremos que muitos são os episódios de pessoas que marcaram época com sua capacidade de entender e compreender as necessidades do outro e principalmente não deixaram se abater pela emoção, controlando de forma eficaz seus impulsos em prol do bem de todos.

É imprescindível saber lidar com os nossos sentimentos para que possamos agregar valor a nossa empresa e consequentemente as pessoas que estão ao nosso redor.

A inteligência emocional está relacionada à aptidão e a habilidade para a automotivação, o autocontrole, a persistência, entre outras características 
essenciais ao alcance de objetivos de interesses comuns.

Goleman (1999:338) afirma que a “inteligência emocional é a capacidade de identificar nossos próprios sentimentos e os dos outros, de motivar a nós mesmos e de gerenciar bem as emoções dentro de nós, e em nossos relacionamentos".

Para Weisinger (1997:14), “a inteligência emocional é simplesmente o uso inteligente das emoções, isto é, fazer intencionalmente com que suas emoções trabalhem a seu favor, usando-as como uma ajuda para ditar seu comportamento e seu raciocínio de maneira a aperfeiçoar seus resultados".

Covey (2005:342) escreve que "ao estudarmos atentamente a literatura relativa à inteligência emocional, veremos que ela sugere primeiro a importância transcendente da QE para a eficácia ao longo prazo e segundo, que ela pode ser desenvolvida”.

Em paráfrise Covey (2005) classifica a inteligência emocional em cinco elementos: autoconsciência, motivação pessoal, autoregulação, empatia e habilidades sociais.

Weisinger (2001:115) escreve as relações entre os diversos colegas de trabalho está relacionado "aquilo que faz com que esses relacionamentos e interações sejam bemsucedidos e beneficiem todos os envolvidos - inclusive você - é a inteligência emocional; a maneira de colocar sua inteligência emocional em ação é reconhecer e reagir ás emoções e aos sentimentos dos outros, orientando-os para a resolução produtiva de uma situação problemática e utilizando-os para ajudar os outros a ajudar a si mesmos".

E complementa "é óbvio que a capacidade de fazer tudo isso beneficia sua posição na sua empresa - não apenas você produz mais, pois encontra consenso e cooperação, como também os outros passam a considerá-lo indispensável na equipe" (WEISINGER,2001:115).

\section{Considerações Finais}

Como podemos observar a inteligência emocional está relacionada a habilidades como: motivar a si mesmo e as outras pessoas, persistir mediante os obstáculos, saber canalizar as emoções em prol de algo positivo, construtivo, ter controle sobre seus sentimentos, desta forma agregando colaboradores motivados e com grande potencial criativo e comprometidos com os objetivos da organização.

Goleman (2001:3), afirma que “os grandes líderes nos mobilizam. Inflamam nossa paixão e inspiram o melhor dentro de nós". E acrescenta que a causa de tamanho comprometimento com a liderança se deve ao fato de como lidar com as emoções.

De acordo com Goleman, para que possamos despertar em nossa equipe esse sentimento entusiástico é fundamental que primeiramente saibamos lidar com os nossos próprios sentimentos, tenhamos equilíbrio para que a nossa equipe sinta-se confiante e satisfeita.

Os líderes de sucesso ao desenvolver a habilidade de controlar suas próprias emoções são capazes de influir na harmonização necessária para o desenvolvimento e retenção de talentos, que infere positivamente na construção de resultados positivos para empresa e para seus liderados.

Por fim, o que podemos concluir na leitura deste artigo é que o líder emocionalmente equilibrado tem uma vantagem competitiva ao saber lidar com suas próprias emoções, pois facilita a interação com as outras pessoas e proporciona a construção de um ambiente de trabalho harmonioso, eficaz e desenvolver equipes de alto desempenho, assim como alinhar todos em prol de objetivos comuns à organização e as pessoas inseridas neste contexto. 


\section{Bibliografía}

1. BARros, Aidil Jesus Paes de, e LEHFELD, Neide Aparecida de Souza.

Fundamentos da Metodologia - Um Guia para Iniciação Científica. São Paulo: Makron Books, 1986.

2. COVEY, Stephen R. $\mathbf{O} \mathbf{8}^{\mathbf{o}}$ Hábito - da Eficácia à Grandeza. Rio de Janeiro: Campus, 2005.

3. DAVIS, Keith. Comportamento Humano nas Organizações. São Paulo: Thomson, 1998.

4. FLEURY, Maria Tereza Leme et al (a). As pessoas na Organização. São Paulo: Gente, 2002.

5. GOLEMAN, Daniel. Trabalhando com a Inteligência Emocional. Rio de Janeiro: Objetiva, 1999.
6. GOLEMAN, Daniel. Inteligência Emocional. Rio de Janeiro: Objetiva, 2001.

7. GOLEMAN, Daniel. O Poder da Inteligência Emocional. Rio de Janeiro: Campus, 2002.

8. HUNTER, James C. O Monge e o Executivo. Rio de Janeiro: Sextante, 2004. 9. SOUZA, César. Você é o Líder da Sua Vida. Rio de Janeiro: Sextante, 2007.

10. WEISINGER, Hendrie. Inteligência Emocional no Trabalho. Rio de Janeiro: Objetiva, 1997.

11. WILLINGHAM, Ron. Gente - o Fator

Humano. São Paulo: Educator, 2001. 